\title{
Post-fire tree regeneration in forests of the Tikhvin Ridge, North-West Russia
}

\author{
Dmitry Danilov ${ }^{1, *}$, Dmitry Zaytsev ${ }^{2}$, and Natalia Belyaeva ${ }^{1}$ \\ ${ }^{1}$ Institute of Forests and Natural Resources, Saint-Petersburg State Forest Technical University named \\ after S.M. Kirov, 194021, Saint-Petersburg, Russian Federation \\ ${ }^{2}$ Leningrad Research Agriculture Institute "Belogorka" Branch of Russian Potato Research Centre, \\ 188338, Leningrad Region, Russian Federation
}

\begin{abstract}
We assessed the effect of ground fires on the success of advanced regeneration of tree species on gentle hilly ridges of terminal moraines of the North-Eastern part of the Leningrad Region. To study the juvenile generation of tree species, we carried out a reconnaissance survey of transects in the forest areas affected by wildfires. The forest stands were 10-12 years old. The stem numbers and heights of the regenerating tree species were recorded. The correlation analysis was used to determine the degree of influence of external factors on forest regeneration, including soil conditions and the burnt area size. We found differences in the species composition of stands with a predominance of deciduous and coniferous species depending on soil and hydrological conditions. We also found a relationship between soil factors and spruce and pine regeneration size in stands with a predominance of coniferous and deciduous species. The soil granulometric composition influenced proportions of coniferous and deciduous trees in post-fire stands. Using the knowledge obtained about the stand composition, we can forecast the future development of forest stands and prescribe the optimal forest management regimes.
\end{abstract}

\section{Introduction}

The effect of fires on forest communities of the boreal zone is both destructive and positive [1-3]. The emergence, growth and destruction of forests, and their territorial distribution and evolution often take place under the active influence of fire. The degree of manifestation of the beneficial effects of fire depends on the climate, the type of biogeocenosis and the stage of its development, as well as on the intensity and duration of fire, and the time since the previous fire. It has been reported that successful regeneration of conifers most often occurs after ground fires of moderate intensity. A large number of publications is devoted to the role of forest fires in the natural dynamics of forest ecosystems. The reason for such a significant interest of researchers towards this problem is obvious. Of all disturbance factors, fires were the most powerful ecological factor determining the structure and dynamics of primeval forests $[6,7,8]$.

${ }^{*}$ Corresponding author: stown200@mail.ru 
Studies of the effect of wild fires on forest stands and subsequent regeneration of tree species have been carried out in many countries, both in the temperate zone and in regions with an arid climate [2-4]. Some studies investigated post-fire succession in various regions $[9,10,11]$. For different tree species, different nature of restoration processes depending on the relief, burnt area size, soil properties, and hydrology has been described [4-6, 9, 10]. Depending on the landscape conditions, post-fire tree stands with various species composition form. They are often different from the initial tree stands $[6,8,9,11,12]$. In various regions, the success of post-fire regeneration has been noted by many authors. At the same time, a number of authors noted that successful regeneration did not always take place in burnt areas $[11,13,14,15]$. To assess the progress of the forest community regeneration after disturbances, the following parameters are often used: the abundance, the number of species, and the structure of dominance $[4,12,13,15,16]$. The process of post-fire replacement of conifers by deciduous species is widespread. The study of forest regeneration at the landscape level makes it possible to prescribe forestry measures for the formation of highly productive forest stands, taking into account the soil and hydrological conditions of areas affected by fires of different intensity. The factors and mechanisms of the long-term recovery dynamics of communities of soil animals in burnt-out areas have not been sufficiently studied. From the standpoint of the modern forest population ecology, natural regeneration of the main forest-forming edificator species is a key cenopopulation and ecosystem process that happens after forest fires [17,18,19,20,21]. Its outcome largely determines the structure, functions and all subsequent dynamics of the forest biogeocenosis, and therefore the subsequent silvicultural activities. A number of questions remain open related to the heterogeneity of the soil cover of burnt areas, the size of the burnt area, and the structure of ecotones between the forest and the burnt area.

Studies of regeneration processes at the landscape level make it possible to prescribe forestry measures for the formation of highly productive tree stands, taking into account soil and hydrological conditions of the sites affected by fires of different intensity.

\section{Methods}

We surveyed 10-12 year-old stands formed after ground fires. The sites were located on gentle ranges of hills of terminal moraines and esker and kame complexes under the Tikhvin Ridge landscape conditions of the Boksitogorsky District, the Leningrad Region, Russia, on clay-loam and peaty soils with different moisture regimes [4, 22]. This landscape is part of the Valdai Hills, the main zone of the marginal glacial formations of the last glaciation within the Leningrad Region. The Valdai Hills are the largest orographic part of the entire North-West of the Russian Plain, being the watershed between the Baltic and the Caspian Sea Basins. This territory is the largest hilly relief strip, including marginal formations of several stages of the last glaciation retreat. The Tikhvin Ridge is a hilly upland in the South-East of the Leningrad Region with altitudes up to $280 \mathrm{~m}$. The relief is a result of accumulation of glacial till of the several stages of the last glaciation. The zone of the marginal glacial formations is characterized by the rugged hilly and lake landscape. There are well-represented moraine hills and ridges, kames, eskers, fluvioglacial deltas of glacial streams, and zvonetses (elevated plateaus, composed of limnoglacial clays). The largest areas feature hilly-moraine topography. The diameters of the hills vary from 300 $500 \mathrm{~m}$ to $1 \mathrm{~km}$, and their relative height is $15-50 \mathrm{~m}$; their shape is round or elongated, the gradient of slopes is $10-25^{\circ}$. In the eastern part of the strip of the marginal glacial formations, the hilly-moraine relief is often significantly smoothed due to the influence of limnoglacial basins. The dominant heights are up to $200 \mathrm{~m}$. The heights above are formed by zvonets groups. Eskers are differently oriented and are $10-15 \mathrm{~km}$ long. 
To evaluate the success of the post-fire tree species regeneration in stands with a predominance of spruce and deciduous species, we carried out exploratory surveys of transects in forest areas affected by ground fires. The plots with the size of $10 \mathrm{~m}^{2}$ were established along transects at a distance of three meters. This method makes it possible to study the factors that determine the growth of woody plants on the given territory [4,23]. In the course of the survey, the undergrowth was divided into three groups: small (up to $0.5 \mathrm{~m}$ tall), medium (0.5-1.5m), and large (above $1.5 \mathrm{~m})$.

These burnt areas belong to the blueberry series of forest types; however, the soils on these post-fire sites differed in their granulometric composition, ranging from sand, sandy loam, and loam to peaty with different moisture regime. The soils in the study areas had been formed by various regenerative processes involving different woody species developing under different conditions. In all plots, the parent mixed pine and spruce stand acted as the source of coniferous regeneration. Therefore, it can be assumed that this factor made an equal contribution in all investigated areas subjected to forest fire. The granulometric texture of soils was determined by organoleptic methods (Table 1) [24].

Table 1. Soil indices.

\begin{tabular}{|c|l|}
\hline Index & \multicolumn{1}{c|}{ Granulometry } \\
\hline 1 & Sandy soil \\
\hline 2 & Sandy-loam fresh soil \\
\hline 3 & Sandy-loam waterlogged soil \\
\hline 4 & Fresh loam soil \\
\hline 5 & Waterlogged loam soil \\
\hline 6 & Peat soil \\
\hline
\end{tabular}

To analyze the relationships, we calculated the correlation ratio $\eta$ of the dependent variable $\mathrm{Y}$ to the independent variable $\mathrm{X}$, which can be obtained from the ratio of the intergroup variance to the total variance [25-27]. The theoretical correlation ratio is determined by the formula:

$$
\eta=\sqrt{1-} \frac{\sigma_{\text {res. }}^{2}}{\sigma^{2}}=\frac{\delta^{2}}{\sigma^{2}}
$$

Where: $\delta^{2}$ is the variance of the predicted values of the dependent variable, i.e. calculated by the regression equation; $\sigma^{2}$ is the variance of empirical (actual) values of the dependent variable; $\sigma_{\text {res }}^{2}$ is the residual variance. The relationship between the indicators was assessed on the basis of the theoretical correlation using the Chaddock scale [25].

Table 2. Assessment of relationship based on theoretical correlation (Chaddock scale).

\begin{tabular}{|l|l|l|l|}
\hline \multicolumn{1}{|c|}{ Value } & \multicolumn{1}{|c|}{ Relationship } & \multicolumn{1}{c|}{ Value } & Relationship \\
\hline$\eta=0$ & None & $0.5 \leq \eta<0.7$ & Considerable \\
\hline $0<\eta<0.2$ & Very weak & $0.7 \leq \eta<0.9$ & Strong \\
\hline $0.2 \leq \eta<0.3$ & Weak & $0.9 \leq \eta<1$ & Very strong \\
\hline $0.3 \leq \eta<0.5$ & Moderate & $\eta=1$ & Functional \\
\hline
\end{tabular}

\section{Results}

In forests on sandy-loam, loamy, and peaty soils with various moisture regimes, the burnt areas were 1-3.3ha in size. In the areas affected by ground fire, we measured the size of regenerating coniferous and deciduous trees. To determine the degree of success of forest regeneration, all newly emerged trees were allocated to the size categories according to the current forestry regulations and rules [15,23]. Depending on the predominance of a 
particular species in the stand composition, post-fire young stands with different height structures can form. The economically valuable species regeneration success should be assessed from the point of view of forestry and the subsequent care of young stands. In post-fire stands on clay-loam fresh soils dominated by spruce undergrowth, we observed that the latter belonged mostly to the medium and large size categories (Fig. 1). The pine undergrowth was also represented by medium and large categories. There was a significant quantity of pine and spruce of the small size category. However, this size category was dominated by spruce. In general, both species numbers suggested a successful development of spruce and pine stands in the future. Only the number of deciduous species had to be adjusted (Fig. 1). In spruce-dominated stands on peaty soils, large individuals prevailed; there was also medium-size undergrowth with a total number of over 2000 stems per ha, including small undergrowth. The pine undergrowth was mostly of the large and medium sizes and represented by 450 stems per ha on average. In post-fire young stands dominated by spruce, there were 350-700 stems per ha of birch undergrowth, and 150-350 stems per ha of aspen undergrowth (Fig. 1).
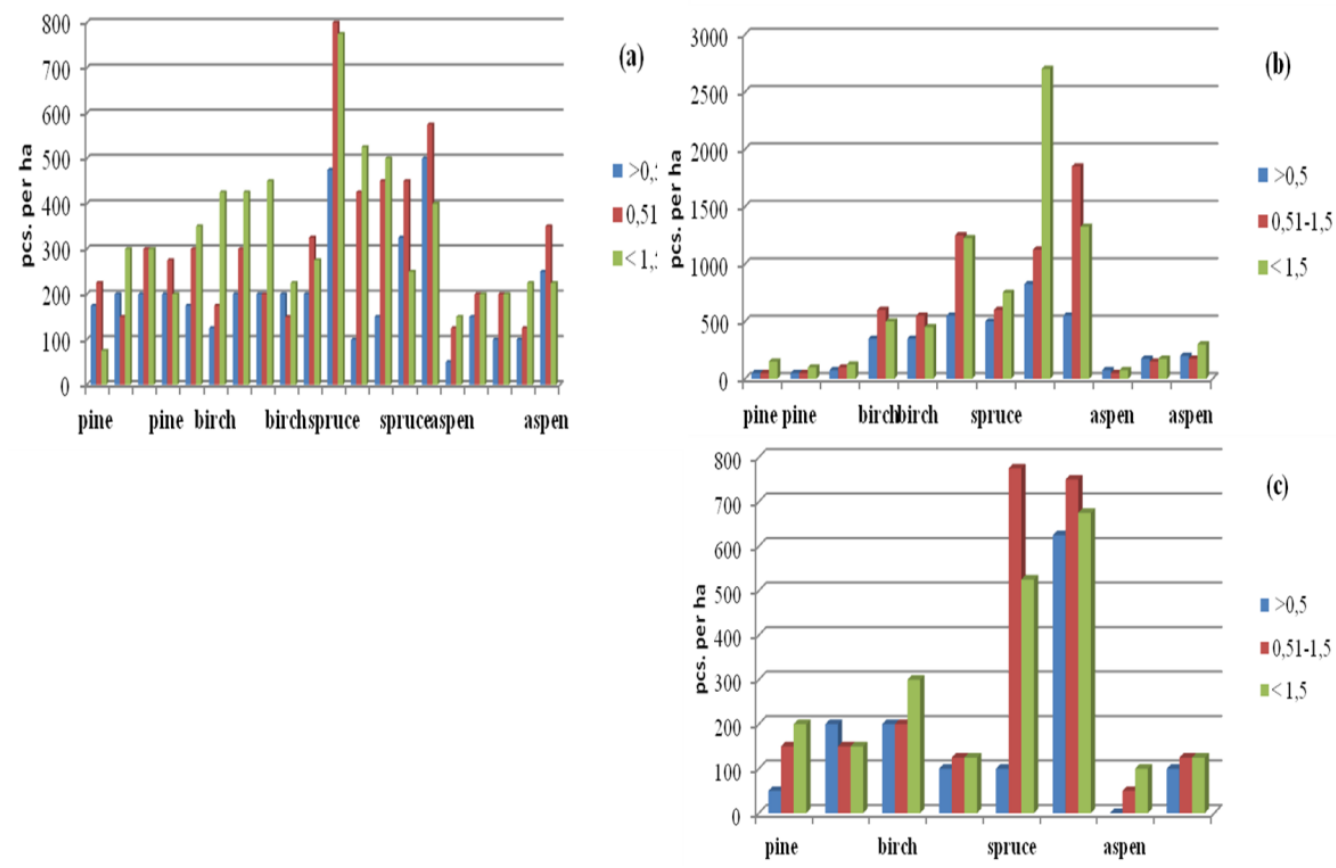

Fig. 1. Distribution of tree species undergrowth by size category in stands dominated by spruce on loamy (a), loamy gley (b), and peaty soils (c).

The comparative analysis of sufficient and excessive moisture regimes demonstrated that the largest number of deciduous species was on wet sandy-loam soils; on average, more than 2000 stems of birch trees and the same number of aspen. There were about 1200 stems per ha of pine and spruce (Fig. 2). The coniferous undergrowth was more abundant on fertile peaty soils: about 1500 pine trees and about 1000 spruce trees per ha. There were over 1500 stems per ha of birch and about 1000 stems per ha of aspen (Fig. 2). 

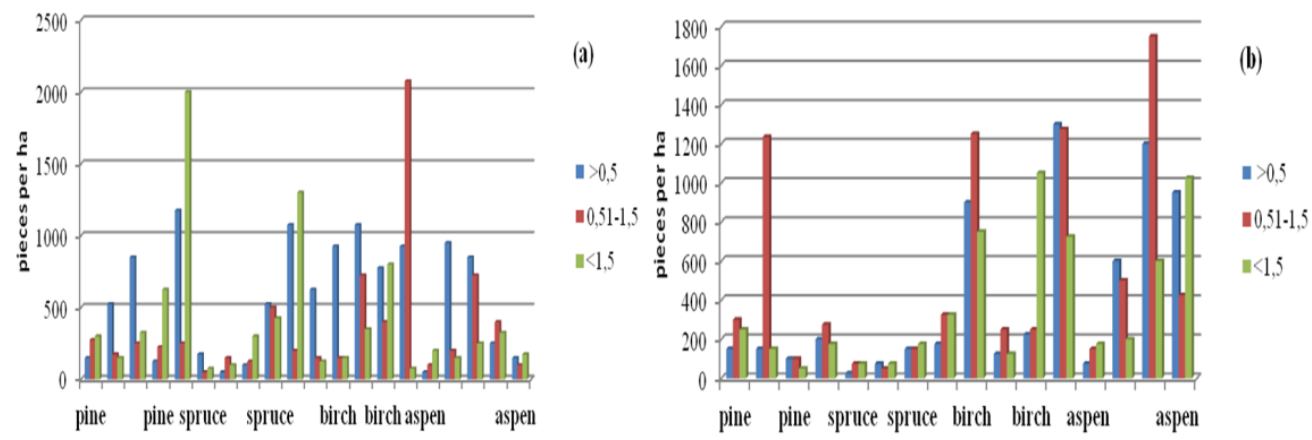

Fig. 2. Distribution of tree species undergrowth by size categories in stands dominated by deciduous species on sandy loam (a) and peaty soils (b).

It should be noted that the pine undergrowth was represented mostly by large and medium trees on both soil phases. The spruce undergrowth was less abundant and was represented by approximately the same number of trees in all size categories. Medium and large individuals of deciduous species predominated. Low numbers of coniferous species, 1200 stems per ha, and about 4000 stems per ha of birch and aspen suggest the formation of mixed coniferous-deciduous stands with all species in equal proportions on sandy loam and clay-loam soils. At this age stage, a complete removal of aspen would result in a sufficient number of pine and spruce trees on waterlogged soils. To achieve the development of relatively pure coniferous stands, it would be sufficient to remove deciduous species.

\section{Discussion}

The quantitative representation of coniferous and deciduous species in a post-fire stand, as well as the height structure of the stand, depend on a number of environmental conditions, such as the size of the burnt area, the seed source in the form of a parent stand, and other factors. Depending on the granulometric composition of soils, the process of regeneration of tree species can result in the subsequent dominance of one or another coniferous or deciduous species. A survey of the sites showed that the ground fire had a different effect on the soil complexes of the research objects with young post-fire stands.

The obtained results indicate that after fire, heterogeneities in the soil complex lead to a different number of species under similar granulometric conditions. In stands dominated by the spruce undergrowth, the correlation between the number of spruce trees and the granulometric texture of the soil was inverse and significant $(\mathrm{R}=0.42)$. As the soil texture became heavier, the number of spruce trees increased. In post-fire sites dominated by spruce, the correlation between the tree numbers and the granulometric texture was sufficiently described by a second-order polynomial. A strong correlation $(\mathrm{R}=0.99)$ was observed between the granulometric texture and the pine undergrowth numbers. However, it should be noted that the highest numbers of the pine and spruce undergrowth were recorded on fresh clay-loam soils. After the fire, the most favourable environment for the spruce regeneration was in areas with more waterlogged soils (Fig. 3).

When the deciduous species were considered, the number of birch and aspen trees also depended on the granulometric texture of soils. For birch, there was a stronger correlation between the number of trees and the granulometric texture of soils $(\mathrm{R}=0.64)$ than in young stands where the pine undergrowth prevailed (Fig. 4). In post-fire stands with a predominance of deciduous species, there was a linear relationship between the number of all species and the granulometric texture of the two soil types: fresh sandy loam and peaty soil (Fig. 4). For the pine and spruce undergrowth in these stands, significant correlations 
with soil conditions were revealed, with $\mathrm{R}=0.71$ for pine, and $\mathrm{R}=0.69$ for spruce. A stronger correlation was observed for deciduous species. For birch, the correlation coefficient was $\mathrm{R}=0.85$, and for aspen, $\mathrm{R}=0.86$, which indicated more favourable conditions for post-fire regeneration of deciduous species on these soil phases (Fig. 4).
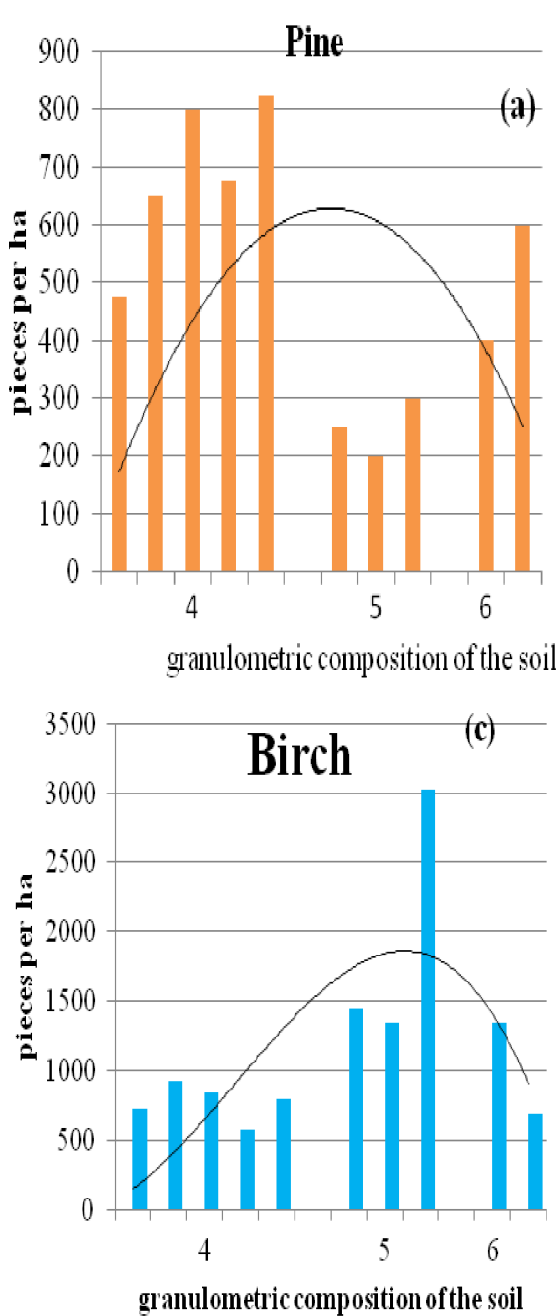

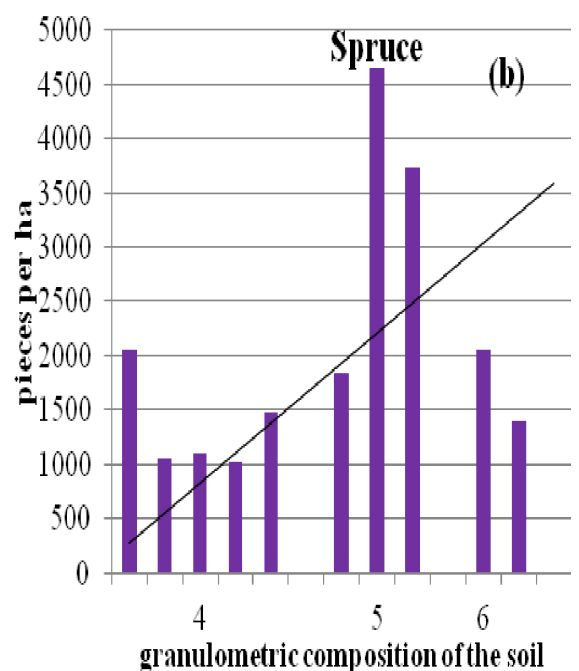

(d)

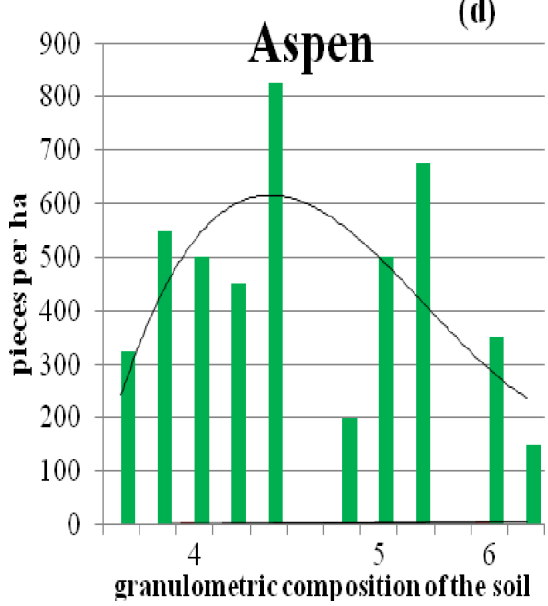

Fig. 3. The influence of the particle size distribution of the soil on the quantity of undergrowth of spruce, pine, birch and aspen in stands dominated by spruce, where, 4- loamy soils; 5 - loamy gley soils; 6- peaty soils. 

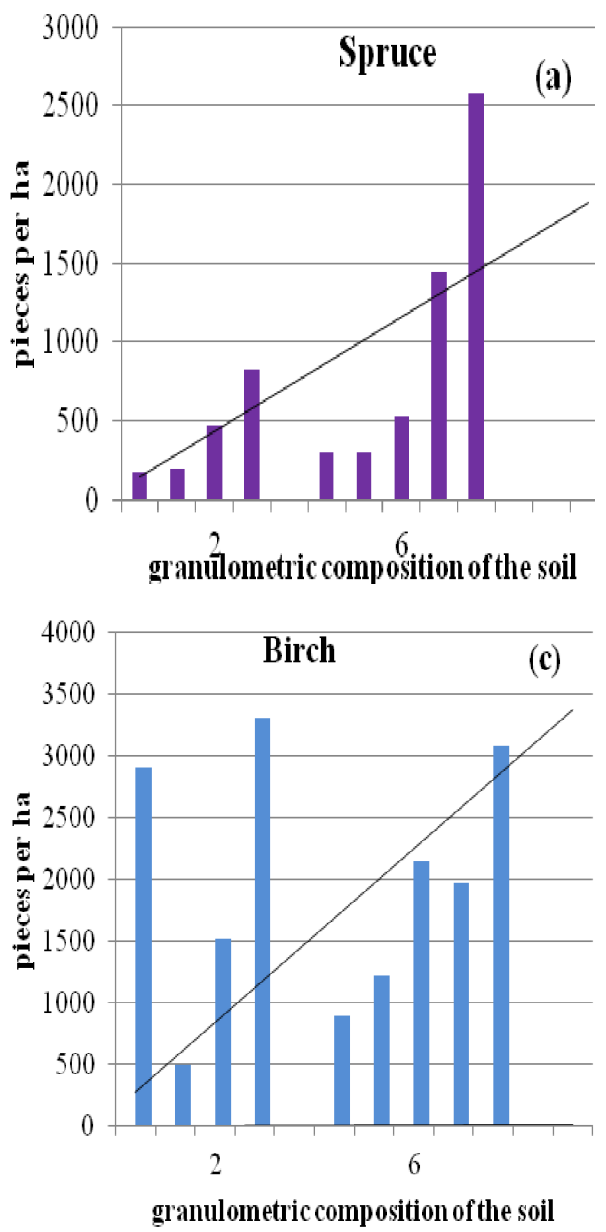

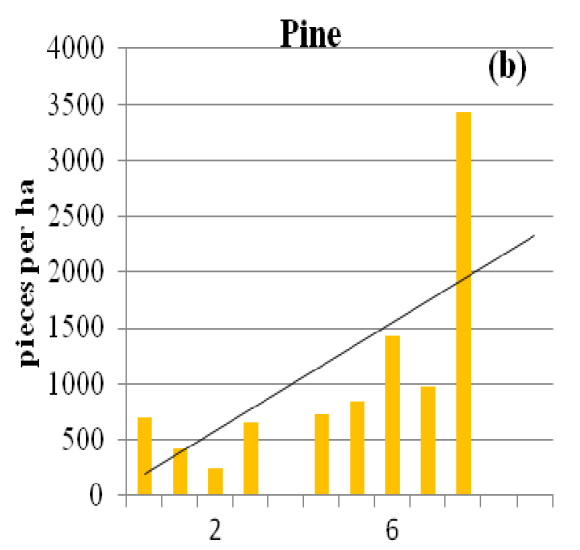

granulometric comp osition of the soil

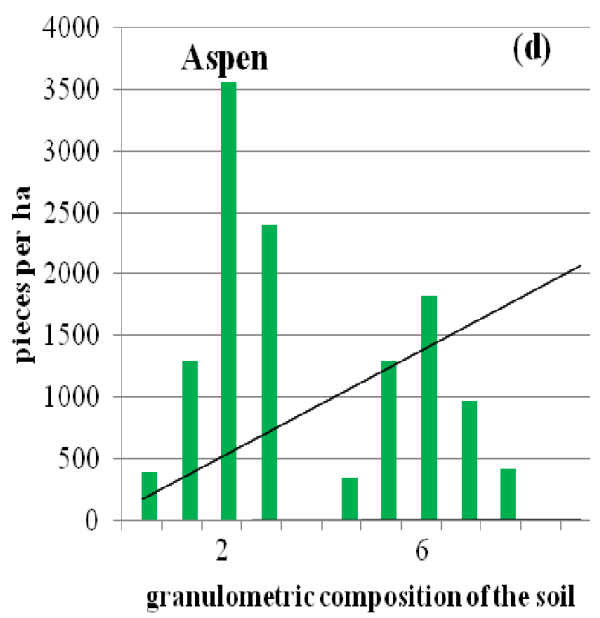

Fig. 4. The influence of the particle size distribution of the soil on the quantity of undergrowth of spruce, pine, birch and aspen in stands dominated by deciduous species, where, 2- sandy loam moist soils; 6- peaty soils.

In general, at this stage, deciduous species do not have a large competitive effect on conifers, and the timely regulation of their numbers makes it possible to form a pure pinespruce stand in the given soil conditions. The analysis of the post-fire regeneration of tree species at the research sites shows that there is a steady increase in the percentage of conifers, since there was a sufficient amount of spruce and pine regeneration of the large and medium size categories. Timely removal of deciduous species will help to produce pure spruce-pine stands in the future.

On sandy soils, given the insufficient amount of coniferous undergrowth and the predominance of post-fire regeneration of birch and aspen, the formation of a coniferousbirch stand with an equal share of species in the stand composition appears to be an optimal solution. At this age stage, it is necessary to completely remove aspen regeneration on waterlogged soils, which will lead to an increase in the number of pine and spruce offspring sufficient for the subsequent formation of an almost pure coniferous stand. 


\section{Conclusion}

In forest sites affected by ground fires, soil conditions affect the development of post-fire vegetation. Our results suggest that this is due to the differences in the granulometric texture of the soils.

In general, we did not observe competitive advantage of deciduous species over spruce and pine undergrowth. Timely removal of deciduous species would allow the development of stands dominated by coniferous species in the given soil conditions.

The analysis of post-fire regeneration of tree species suggests a steady development of coniferous stands since there was a sufficient number of spruce and pine undergrowth of large and medium size categories. Timely removal of deciduous trees will allow the development of mixed spruce-pine stands or mixed coniferous-deciduous stands dominated by spruce and pine.

\section{References}

1. E.S. Artsybashev, Proc. Saint-Petersburg Forestry Research Institute, 1, 4 (2018)

2. J. Minor, A.F. Donald, G.A. Barron-Gafford, Forests, 8, 221 (2017)

3. A.A. Malashchuk, D.A Philippov, Ecosystem Transformation, 4, 1 (2021)

4. D.A. Danilov, I.M. Anisimova, N.V. Belyaeva, I.A. Kazi, IOP Conf. Ser.: Earth Environ. Sci., 574 (2020)

5. P.A Tarasov, V.A Ivanov, G.A Ivanova, Eurasian Soil Sc., 44 (2011)

6. D.J. Brown, I. Mali, M.R. J. Forstner, Fish Wildl. Manag., 5 (2014)

7. S. Archibald, C.E.R. Lehmann, J.L. Gomez-Dans, R.A. Bradstock, Proc. Nat. Acad. Sci. USA, 110, (2013)

8. T.H. Wallenius, S. Lilja, T. Kuuluvainen, For. Ecol. Manag., 250, 89 (2007)

9. M. Lindbladha, M. Niklassona, S.G. Nilsson, Biol. Conserv., 114, 231 (2003)

10. J. Rolstad, Y.L. Blanck, K.O. Storaunet, Ecol. Monogr., 87, 219 (2017)

11. P.S. Nikolova, B. Rohnerb, J. Zellb, P. Branga, For. Ecol. Manag., 448, 278 (2019)

12. H. Pretzsch, E.K. Zenner, For. Ecosyst., 4 (2017)

13. N.I. Stavrova, I.B. Kalimova, V.V. Gorshkov, I.V. Drozdova, N.V. AlekseevaPopova, I.Y. Bakkal, Eurasian Soil Sci., 52, 218 (2019)

14. J. Minor, D.A. Falk, G.A. Barron-Gafford, Forests, 8, 1 (2017)

15. D.A. Danilov, D.V. Gusev, N.V. Belyaeva, IOP Conf. Ser.: Earth Environ. Sci., 574 (2020)

16. A. Gromtsev, Silva Fenn., 36, 41 (2002)

17. S.V. Knyazeva, S.P. Eydlina, For. Sci. Iss., 1, 1 (2018)

18. E. Marcolin, R. Marzano, A. Vitali, M. Garbarino, E. Lingua, Forests, 10 (2019)

19. A. Perera, L. Buse, Ecology of Wildfire Residuals in Boreal Forests (Oxford, WileyBlackwell, 2014)

20. T.B. Jain, D.S. Pilliod, R.T. Graham, L.B. Lentile, J.E. Sandquist, Forests, 3, 445 (2012)

21. F. Tedim, G. Xanthopoulos, V. Leone, Risks and Disasters (Elsevier, Oxford, 2015)

22. V.A. Shirokova, Tikhvin water system: Past and Present (Akkolit, Moscow, 2013) 
23. A.V. Gryazkin, Patent № 2084129 (Russian Federation, 1997)

24. N. Ryzhkova, North-West Russia For. Ecol. Manag., 459 (2020)

25. M. Gardener, Statistics for Ecologists Using R and Excel (Pelagic Publishing, 2017)

26. G. Hui, G. Zhang, Z. Zhao, Y. Aiming, Curr. Forestry Rep., 5, 142 (2019)

27. G. Certini, Oecologia, 143, 1 (2005) 